\title{
Design of Sugar Bucket Elevator and Roller Conveyor Chain for 20 Tonnes per Hour Capacity
}

\author{
Hemlata H.Mulik ${ }^{\# 1}$, Bhaskar D.Gaikwad ${ }^{* 2}$ \\ ${ }^{I} P G$ Student, Mechanical Engineering Department, SVERI's COE Pandharpur, Solapur University, Maharashtra, India \\ ${ }^{2}$ Assistant professor, Mechanical Engineering Department, SVERI's COE Pandharpur, Solapur University, Maharashtra, India
}

\begin{abstract}
Roller conveyor chains are commonly used to transport goods in production lines or assembly lines, such as pallets, cars or steel coils. They are sometimes used in severe environments, soiled with water, foreign particles, chemicals or other contaminants. Normal use will result in wear of the components of the chain which can lead to unexpected failure and costly production downtime. Today, few literatures on the wear of conveyor chain are available and there are almost no reliable test-rigs to generate and measure chain wear in a reproducible manner. In this paper the different components of roller conveyor chains are designed for sugar bucket elevator used in sugar industries for $\mathbf{2 0}$ tonnes per hour capacity and the loading conditions are described. Additionally, the advantages of chain drive as compared with other drives are discussed. The chain wear mechanisms found in literature are listed. Abrasive and adhesive wear between pin, bushing, and roller are also discussed.
\end{abstract}

Keywords- Roller conveyor chain, Bucket elevator, material properties

\section{INTRODUCTION}

The Roller conveyor chains are generally used in production or assembly lines where large objects need to be conveyed. Typical applications of roller conveyors are carrier conveyors for the transport of steel coils in a steel plant or slat conveyors that carry objects. Other examples are conveying pallets, treestumps or even whole cars. Wheeled cars, for example, can be carried by the chain but can also be pulled by the chain. Applications can be divided in two basic conveying modes: -The material is supported and carried entirely by the chain and attachments.

-The chain does not support the material, but it is pushed, pulled or scraped.

Roller conveyor chains differ from transmission roller chains such as a bicycle chain, which is used to transfer torque instead of conveying goods. Conveyor chains have a large pitch which is efficient in bridging large distances with fewer shackles; they generally have thicker side plates and rollers with large diameter. Therefore they can withstand higher tensile and shock loads than transmission chains. Furthermore they can bear large amounts of wear before breakage occurs. A typical conveyor chain is constructed with two different types of shackles: the roller link (or inner link) and the pin link (or outer link), see Figure 1. The roller link consists of two steel bushings that are press-fitted inside the roller link plates, while the pin link consists out of two steel pins pressfitted inside the pin link plates. To prevent disengaging of plates and pins, riveted pins or t-pins (as shown) are used.

Conveyor chains can be loaded in two ways: the force can be applied on the side plates by use of attachments which are connected to the side plates, see Figure 1. Alternately the force can be applied on the pins. Therefore hollow pins and axles instead of solid pins (as shown) are used. The rollers transfer the normal force, due to the weight of the conveyed objects, to the track. The driving sprocket exerts a force on the chain to pull the load, these results in a tensile force inside the chain which must be large enough to overcome the sliding friction between roller or bushing and the rolling friction between roller and track. Additionally the chain is pre-stressed by the sprockets; this will result in a raise of tensile force. To transfer this tensile force from one shackle to another, bushing and pin will act together as a bearing.

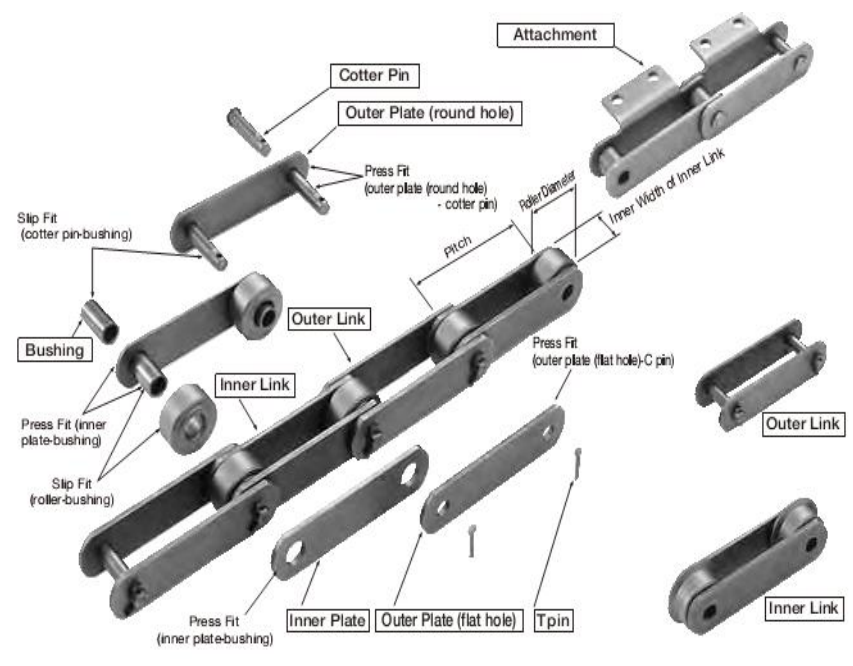

Fig .1: Basic structure of a roller conveyor chain

\section{COMPONENTS OF ROLLER CONVEYOR CHAIN}

1. Pin

The most important role of the pin is connecting the inner link to the outer link. Along with the plate, it receives chain tension along the direction of travel while receiving vertical reactive forces from the conveyed items. The outer diameter of the pin suffers wear from sliding against the bushing inner diameter when the chain articulates. The pin is an essential strength bearing part and requires high wear resistance.

\section{Bushing}

The bushing is a strength-bearing part, receiving tension from the chain during sprocket engagement, but its major role is as a bearing part. The outer diameter of the bushing suffers wear from sliding against the roller inner diameter during roller rotation, while the bushing inner diameter suffers wear from sliding against the outer diameter of the pin when the chain 
articulates. Bushing inner diameter wear is directly Where, expressible as pitch elongation.

\section{Roller}

Forms a slip fit with the bushing. Rotates when engaging with the sprocket, while alleviating the shock and wear from the teeth. Rotation also lowers running resistance.

\section{Plate}

The plate mainly receives the tensile load along the chain's direction of travel while receiving vertical reactive forces while supporting the conveyed item. The outer plate and inner plate slide against each other during chain articulation, as well as against the sides of the sprocket teeth during sprocket engagement. Plate holes are either round or flat.

\section{Attachments}

They are used for attaching items like buckets to the chain.

\section{Split pin}

After the outer plate is press-fitted to the pin, a $\mathrm{T}$ pin is inserted and bent to prevent the pin from falling out.

\section{A. Chain Drive}

Though the sugar industries are using belt drive for bucket elevator the chain drive is more efficient due to the following advantages:

1. As no slip or creep takes place in chain drive, hence perfect velocity ratio is obtained.

2. Since the chains are made of metal, therefore they occupy less space in width than a belt or rope drive.

3. It gives high transmission efficiency up to $98 \%$.

4. Chain does not require initial tension. Therefore forces acting on shafts and bearings are reduced.

5. It transmits more power than belts.

6. It can be operated under adverse temperature and atmospheric conditions.

7. Can be easily replaced.

8. Can be used for short as well as long centre distances.

9. It gives fewer loads on the shafts.

III. Design CAlculations FOR SUgar Bucket ELEVATOR

For bucket elevator using engineering steel bushed straight sidebar roller conveyor chain in which chain rides on tracks generally used for super capacity elevators. Prior to selecting the chain and sprockets, the following should be known:

- Required capacity in ton/hr

- Elevator chain and bucket speed in $\mathrm{ft} / \mathrm{min}$

- Distance between the sprocket centers

- Size of the elevator buckets

- Weight of moving parts

- Weight of the material per foot of elevator as determined by equation:

$$
W=\frac{33.33 T}{S}
$$

$\mathrm{T}$ is the capacity in ton/hr

$\mathrm{S}$ is the chain and bucket speed in $\mathrm{ft} / \mathrm{min}$

$\mathrm{W}$ is the weight of the material per foot of elevator

$$
\begin{aligned}
W & =\frac{33.33 \times 20}{196.850393701} \\
& =\frac{666.6}{196.850393701} \\
& =3.3863186 \text { per foot }
\end{aligned}
$$

- Aeration for pulverized material and its effect on material density

- Service conditions such as the abrasiveness of the material; clean corrosive, hot or cold environment, degree and frequency of shock, operating hours per day

Some of these quantities can only be approximated at this point. For example, the user does not know the weight of the chain until we select it, so a back check should be made when the selection is completed.

Bucket of sugar bucket elevator is designed using Design data- Data book of engineers PSG college of Technology, Coimbatore, India.

Equation:

$$
\frac{\mathrm{i}_{0}}{\mathrm{a}}=\frac{\mathrm{Q}}{3.6 \mathrm{v} \Psi_{\mathrm{\rho}}}
$$

Where,

1. $i_{0}=$ Capacity of each bucket, litter

2. $a=$ pitch of bucket, $m$ $\simeq(2.5$ to 3$) \mathrm{h}$

3. $\mathrm{h}=$ height of bucket at the chain end, $\mathrm{m}$

4. $v=$ chain velocity, $\mathrm{m} / \mathrm{s}$

5. $\mathrm{p}=$ bulk density of conveyed material, tone/Cu.m

6. $\Psi=$ bucket loading efficiency (table 1, p. 9.24)

7. $\mathrm{Q}=$ capacity of elevator, tone $/ \mathrm{hr}$

8. $\frac{\tilde{i}_{a}}{a}=$ values from table $2, p .24$

$\frac{\mathrm{i}_{\mathrm{o}}}{\mathrm{a}}=\frac{20}{3.6 \times 0.7 \times 0.85 \times 0.8}$

$\underline{\mathrm{i}_{0}}=11.6713352$

a

$$
\mathrm{i}_{\mathrm{o}}=11.6713352 \times 0.11
$$

$\mathrm{i}_{\mathrm{o}}=1.283846$ liter

$\mathrm{i}_{\mathrm{o}}=0.001283846 \mathrm{~m}^{3}$

Width of Bucket $=160 \mathrm{~mm}$

$$
\mathrm{A} \geq \mathrm{a}_{\max } \mathrm{m}
$$


Where,

1. $A=$ projection of bucket from chain face, $\mathrm{mm}$

2. $a_{\max }=$ dimension of the largest lump of material conveyed, $\mathrm{mm}$

3. $m=2$ to 2.5 if $20 \%$ of material is of size $\mathrm{a}_{\max }$ size $\mathrm{a}_{\max }$

$=4.25$ to 4.75 if 50 to $100 \%$ of the material is of

$$
\begin{aligned}
& \mathrm{S}_{\max }=1.15 \mathrm{H}\left(\mathrm{q}+\mathrm{k}_{1} \mathrm{q}_{0}\right) \\
& \mathrm{q}=\frac{\mathrm{Q}}{3.6 \mathrm{v}}
\end{aligned}
$$

Where,

1. $S_{\max }=$ dimension of the largest lump of material conveyed, mm

2. $\mathrm{H}=$ height to which load is elevated, $\mathrm{m}$

3. $q=$ wt. of load/ meter of elevator, $\mathrm{kg} / \mathrm{m}$

4. $\mathrm{k}_{1}=$ factor of resistance, see table $3, \mathrm{p} .9 .25$

5. $q_{0}=$ wt. per meter of chain with buckets, $\mathrm{kgf} / \mathrm{m}$

$\simeq \mathrm{K}_{2} \mathrm{Q} \quad$ (for $\mathrm{K}_{2}$ see table 3 )

$$
\begin{gathered}
\mathrm{q}=\frac{\mathrm{Q}}{3.6 \mathrm{~V}} \\
=\frac{20}{3.6 \times 0.7} \\
=7.936507 \mathrm{kgf} / \mathrm{m} \\
\mathrm{q}_{0}=\mathrm{K}_{2} \times \mathrm{Q} \\
=1.2 \times 20 \\
=24 \mathrm{kgf} / \mathrm{m} \\
=1.15 \times 10.5(7.936507+1.5 \times 24) \\
=530.533322 \mathrm{kgf} / \mathrm{m}
\end{gathered}
$$

Power on the drive shaft:

$$
\mathrm{N}=\frac{\mathrm{QH}}{367}\left(1.15+\mathrm{K}_{2} \mathrm{~K}_{3} \mathrm{v}\right)
$$

Where,

$\mathrm{N}$ = power, $\mathrm{kW}$

$\mathrm{K}_{3}=$ factor, see table 3, p. 9.25

$$
\mathrm{N}=\frac{20 \times 10.5}{367}(1.15+1.2 \times 1.3 \times 0.7)
$$

$$
=1.2828882 \mathrm{~kW}
$$

Dimensions \& capacity of Buckets

Type of Bucket: Deep

Width B, mm: 135-400

Height h, mm: 100-240

Capacity $\mathrm{I}_{\alpha}$ litre: $0.75-14.5$

\section{DESIGN CALCULATIONS FOR ROLLER CONVEYOR} CHAIN COMPONENTS

Design of pin in shearing:

$$
\begin{aligned}
& \mathrm{T}=\frac{\mathrm{F}}{\mathrm{A}} \\
& \mathrm{T}=\frac{\mathrm{F}}{2 \times \frac{\pi}{4} \mathrm{~d}^{2}}
\end{aligned}
$$

According to maximum shear stress theory,

$$
\mathrm{T}=\frac{\mathrm{S}_{\mathrm{ut}}}{\mathrm{f} . \mathrm{s} \text {. }}
$$

For pin we have selected case hardened, refined \& quenched material 17Mn1Cr95. So using design data book we get the values of $S_{u t}$ and taking factor of safety 3 or 3.5 for pin.

$$
\begin{aligned}
\tau & =\frac{80}{3} \\
& =26.6667 \mathrm{kgf} / \mathrm{mm}^{2}
\end{aligned}
$$

Now,

$$
\begin{aligned}
\mathrm{T} & =\frac{20 \times 10^{\mathrm{I}}}{\frac{\pi}{2} \mathrm{~d}^{2}} \\
26.6667 & =\frac{40000}{\pi \mathrm{d}^{2}} \\
\mathrm{~d}^{2} & =\frac{40000}{83.7758} \\
\mathrm{~d} & =21.8509 \mathrm{~mm}
\end{aligned}
$$

Approximately pin diameter is equal to $22 \mathrm{~mm}$ or $23 \mathrm{~mm}$ and head diameter $28 \mathrm{~mm}$ with length of pin $98 \mathrm{~mm}$ as per Indian standard specification IS 8466:1990.

Design of Link Plate:

For link plates we have selected plain carbon steel material $\mathrm{C}_{45}$.

According to maximum shear theory,

$\mathrm{S}_{\mathrm{sy}}=0.5 \mathrm{~S}_{\mathrm{ut}}$

$$
\begin{aligned}
& \text { Now, } \quad \sigma=\frac{0.5 \text { Sut }}{f s_{\text {s. }}} \\
& \sigma=\frac{0.5 \times 600}{8} \\
& \sigma=37.5 \mathrm{~N} / \mathrm{mm}^{2} \\
& \sigma=\frac{F}{A} \\
& \sigma=\frac{20000}{w \times t \times 4}
\end{aligned}
$$

Now, assuming thickness for plate $10 \mathrm{~mm}$ as per Indian standard specification IS 8466:1990.

$$
\begin{gathered}
37.5=\frac{20000}{w \times 10 \times 4} \\
w=13.3333333 \mathrm{~mm} \\
w \approx 14 \mathrm{~mm}
\end{gathered}
$$

Total width of link plate $=14+14+27$

$$
=55 \mathrm{~mm}
$$

Pitch of chain link plate and other component dimensions: From Standard handbook of chain, standard pitch for the chain 
is selected. For sugar elevator buckets 6 inch pitch chain will produce the rated capacity of 7.625 litres. So selecting 6 inch i.e. $152.40 \mathrm{~mm}$ pitch for chain plate.

Now, total length of plate $=152.4+2(14 \times 1.5)+30$

$$
=224.4 \mathrm{~mm}
$$

Approximately total length of link plates $=225 \mathrm{~mm}$

So the final dimensions for all plate sizes are $225 \times 55 \times 10$ $\mathrm{mm}$. In the same manner from all above calculations roller of diameter $75 \mathrm{~mm}$ and length $56 \mathrm{~mm}$. Bush of internal diameter $23.3 \mathrm{~mm}$, outer diameter $30 \mathrm{~mm}$ and total length $55 \mathrm{~mm}$. Also the standard size split pin, are taken as per Indian standard specification.

\section{MATERIAL PROPERTIES OF CHAIN PARTS}

TABLE I

PROPERTIES OF MATERIAL

\section{CONCLUSIONS}

The Chain is the most important element of the industrial processes required for transmitting power and conveying of materials. As these chains operate under various forces, failure

\begin{tabular}{|c|c|c|c|}
\hline $\begin{array}{c}\text { Properties of } \\
\text { Material }\end{array}$ & $\begin{array}{c}\text { Plain Carbon } \\
\text { Steel }\end{array}$ & $\begin{array}{c}\text { M.S. (Forged } \\
\text { steel) }\end{array}$ & 17Mn1Cr95 \\
\hline $\begin{array}{c}\text { Young's } \\
\text { Modulus(E) }\end{array}$ & $210 \mathrm{GPa}$ & $210 \mathrm{GPa}$ & $210 \mathrm{GPa}$ \\
\hline Poisson's Ratio & 0.3 & 0.3 & 0.28 \\
\hline Density & $7850 \mathrm{~kg} / \mathrm{m}^{3}$ & $7850 \mathrm{~kg} / \mathrm{m}^{3}$ & $7800 \mathrm{~kg} / \mathrm{m}^{3}$ \\
\hline Tensile Strength & $750 \mathrm{Mpa}$ & $500 \mathrm{MPa}$ & $800 \mathrm{MPa}$ \\
\hline
\end{tabular}

of chain assembly is the major problem. Causes of these failures are improper material selection, uncertainties in manufacturing, faulty manufacturing processes. The objective of this study is to design the roller conveyor chain for sugar bucket elevator system taking into account recent developments.

\section{REFERENCES}

[1] U. S. Tsubaki, The Complete Guide to Chain, $1^{\text {st }}$ English language Edition, 1997.

[2] V. Kerremans, T. Rolly, P. De Pauw, J. Sukumaran, Perez Delgado, "Wear of conveyor chain with polymer rollers," Sustainable construction and design 2011.

[3] Snehal Patel, Sumant Patel, Jigar Patel Douglas, D. Kuhlmann, "A Review on Design and Analysis of Bucket Elevator", Vol. 2, Issue 5, September- October 2012, pp.018-022.

[4] Design Data-Data book of engineers PSG college of Technology, Coimbatore, India.

[5] Standard Handbook of Chains- Chains for Power Transmission and Material Handling, American Chain Association, Second Edition, 2006.

[6] Renold Conveyor Chain Catalogue.

[7] V. B. Bhandari, Design of machine Elements, The McGraw-Hill Companies, Second Edition. 